\title{
RECOMENDACIONES EN GESTANTES DURANTE LA PANDEMIA COVID-19
}

\section{RECOMMENDATIONS IN PREGNANTS DURING THE PANDEMIC COVID-19}

\author{
Juan Pedro Matzumura Kasano¹, Ither Sandoval Díaz¹, Luis Meza Santibáñez¹
}

\section{INTRODUCCIÓN}

Se sabe que las mujeres embarazadas experimentan cambios inmunológicos y fisiológicos que pueden hacerlas más susceptibles a las infecciones respiratorias virales, incluido COVID-19 (SARS-CoV-2,). Diversos estudios revelaron que las mujeres embarazadas con diferentes enfermedades respiratorias virales tenían un alto riesgo de desarrollar complicaciones obstétricas y resultados adversos perinatales en comparación con las mujeres no grávidas, debido a los cambios en las respuestas inmunes ${ }^{1-8}$.

También sabemos que las mujeres embarazadas pueden estar en riesgo de enfermedad grave, morbilidad o mortalidad en comparación con la población general, tal y como se observa en los casos de otras infecciones por coronavirus relacionadas [incluido el coronavirus del síndrome respiratorio agudo severo (SARS-CoV) y el coronavirus del síndrome respiratorio del Medio Oriente (MERS- CoV)] y otras infecciones respiratorias virales, como la gripe $\mathrm{H} 1 \mathrm{~N} 1$, durante el embarazo.

\section{PERIODO DE INCUBACIÓN}

Inicio de síntomas entre 5 a 6 días después de infección, en promedio (Rango: 1 a 14 días) ${ }^{2}$.

\section{PERIODO DE TRANSMISIBILIDAD}

7 días después del inicio de síntomas (en promedio), pero puede extenderse hasta 14 días. Se estima que la transmisión podría iniciar antes de la presentación de síntomas, aunque esta información aún se encuentra en investigación ${ }^{2}$.

\section{DIAGNÓSTICO CLÍNICO}

Los signos y síntomas de COVID-19 son inespecíficos, con un amplio espectro clínico que puede extenderse desde un caso sin síntomas (asintomático) hasta una neumonía severa y muerte ${ }^{1,2,8,9}$.

El cuadro clínico más frecuente está caracterizado por un síndrome gripal (fiebre, tos, en algunos casos de dificultad respiratoria), que inicia con fiebre leve, con evolución progresiva de la temperatura, y persistencia entre 3 a 4 días, con un posterior descenso, como ha sido observado en casos de influenza ${ }^{1,8,9}$. El diagnóstico depende de la evaluación clínica-epidemiológica y del examen físico ${ }^{1,2,8,9}$.

\section{CONSIDERACIONES ESPECIALES PARA PACIENTES EMBARAZADAS}

Las mujeres embarazadas con infección sospechada o confirmada de COVID-19 deben ser tratadas con terapias de soporte, teniendo en cuenta las adaptaciones fisiológicas del embarazo ${ }^{1}$.

De los casos reportados de Chen y colaboradores, Zhu y colaboradores ${ }^{3,4}$, dado el número limitado de casos, podemos concluir con precaución que de las 18 embarazadas infectadas por COVID-19 todas se infectaron en el tercer trimestre de embarazo y el cuadro clínico que presentan no parece ser más grave que en el resto de la población joven y sana.

\section{TRANSMISIÓN VERTICAL}

Hay escasa evidencia de la transmisión vertical (antes, durante o tras el parto por lactancia materna) en mujeres que adquieren la infección durante el tercer trimestre de embarazo; Solo se ha reportado un caso de un neonato de 40 semanas, hijo de una madre con neumonía y nacido por cesárea, que resultó positivo en una muestra de exudado faríngeo tomada a las 30 horas de vida, estando asintomático ${ }^{6}, 16$ de las 18 embarazadas dieron a luz por cesárea $\mathrm{y}$, aunque los recién nacidos no mostraron infección por COVID-19.

\footnotetext{
Sociedad Peruana de Obstetricia y Ginecología. Lima, Perú.

Autorización: La presente publicación fue autorizada por el Presidente de la Sociedad Peruana de Obstetricia y Ginecología.
}

Citar como: Matzumura JP, Sandoval I, Meza L. Recomendaciones en gestantes durante la pandemia COVID-19. Rev Peru Investig Matern Perinat 2020; 9(1): 59-62.

DOI https://doi.org/10.33421/inmp.2020191

Recibido: 31-03-20 Aprobado: 31-03-20 
La infección perinatal sí puede tener efectos adversos sobre los recién nacidos, como pérdida del bienestar fetal, parto prematuro, distrés respiratorio, trombocitopenia junto con alteración de la función hepática e incluso muerte ${ }^{1,8-10}$.

\section{TRANSMISIÓN HORIZONTAL}

El riesgo de transmisión horizontal (por gotas o por contacto), a través habitualmente de un familiar próximo infectado, es igual que en la población general ${ }^{8-10}$.

\section{ATENCIÓN PRENATAL DURANTE LA CUARENTENA}

Establecer mecanismos para brindar orientación clara y sencilla a toda gestante, familia y comunidad, reforzando la identificación de signos de alarma (fiebre / tos / dificultad para respirar), sobre la condición médica y las posibles complicaciones, mediante mensaje de texto por medio del WhatsApp $8,9,10$.

- Brindar a la familia un número telefónico de emergencia del equipo de salud para consultas.

- Elegir a uno de los miembros de la familia que se hará responsable de la gestante.

- Aquellas gestantes a las que se les ha tomado la muestra para coronavirus pueden ingresar a la página web del INS para conocer el resultado mediante el siguiente link: https://www.ins.gob.pe/resultado_coronavirus/

- Establecer estrategias de monitoreo a través del contacto telefónico o video llamada mientras dure el estado de emergencia de aislamiento domiciliario, con énfasis en aquellas gestantes de riesgo y/o con fecha probable de parto próxima, para una referencia oportuna.

- En el caso de gestantes que viven solas o viven en una casa-pensión (estudiantes, trabajadoras, entre otras), se sugiere coordinar con la gestante sobre la visita domiciliaria, con el seguimiento a través de video llamada. En casos de necesidad se puede hacer uso de las casas de espera maternas, si tienen las condiciones de aislamiento.

- Dentro de la organización de la visita domiciliaria, identificar y establecer cronograma por paciente, garantizándose la entrega del suplemento o tratamiento con ácido fólico y sulfato ferroso a la gestante y/o familiar asignado, por el tiempo que dure la medida de emergencia.

\section{ACTUACIÓN ANTE LA LLEGADA DE UNA EMBARAZADA A URGENCIAS CON SOSPECHA DE COVID-19}

- Garantizar una adecuada atención de las emergencias obstétricas, asignando espacios diferentes a los destinados para la atención de pacientes con COVID-19.
- A toda paciente que acuda con síntomas de infección respiratoria aguda se le colocará una mascarilla quirúrgica. Es la primera medida de protección para el personal sanitario que la atiende y para la población en general.

- El personal sanitario debe establecer de forma rápida si un paciente con infección respiratoria aguda (IRA) cumple los criterios de caso en posible de COVID-19 sobre todo en el triaje de inicio.

- Las pacientes que se identifiquen como casos posibles deberán separarse de otros pacientes, se les pondrá una mascarilla quirúrgica (si no la llevaran puesta ya) y serán conducidas de forma inmediata a una zona de aislamiento. El personal que los acompañe hasta la zona de aislamiento llevará mascarilla quirúrgica.

- Los casos posibles deben permanecer aislados, bajo precauciones de aislamiento por contacto y por gotas. Si el cuadro clínico no lo precisa y se puede garantizar el aislamiento domiciliario, estas personas pueden permanecer en aislamiento en su domicilio, no siendo necesario un ingreso hospitalario, incluso mientras esperan el resultado de la prueba para no someter a la mujer a esperas innecesarias.

- Debe tenerse en cuenta las semanas de embarazo y los potenciales riesgos para el feto:o Por debajo de las 24 semanas de embarazo se comprobará la viabilidad fetal y se seguirá el mismo procedimiento que para los demás pacientes; o Por encima de las 24 semanas se comprobará el bienestar fetal y la paciente permanecerá en observación hasta el resultado de las pruebas diagnósticas. El control del bienestar fetal se realizará mediante ecografía y/o registro cardiotocográfico (RCTG) en función de las semanas de embarazo¹.

- En los casos en los que se considere necesario se ingresará en el centro hospitalario con medidas de aislamiento de contacto y por gotas.

- El control del bienestar fetal se realizará en función de los criterios obstétricos y en función de las semanas de embarazo. Los equipos y material (p. ej. manguitos de tensión arterial) deberán ser desechables o de uso exclusivo de la gestante. Si no puede ser así, se desinfectará después de cada uso, tal y como especifique el fabricante ${ }^{1,2,8-10}$.

\section{TRATAMIENTO}

- El manejo de la mujer embarazada infectada por COVID-19 debe correr a cargo de un equipo multidisciplinar que establezca el lugar más adecuado para el correcto tratamiento del binomio madre-feto y que permita mantener el control y la pronta actuación en caso de deterioro materno o fetal o inicio trabajo de parto prematuro.

- Toda gestante o puérpera sintomática respiratoria para COVID-19 debe ser tratadas con la máxima prioridad 
debido al mayor riesgo de resultados adversos y debe ser hospitalizada para evaluación y manejo por 48 a 72 horas. La paciente con sospecha o confirmada de COVID-19, deben tener acceso a atención especializada, que incluye cuidados obstétricos y perinatales. Con las condiciones de bioseguridad y aislamiento.

- Los principios del tratamiento de la embarazada, al igual que el resto de la población, incluyen:

- Medidas de aislamiento precoz o Control de la infección o Toma de muestras para el diagnóstico de COVID-19 y otros virus respiratorios

- Oxigenoterapia si es necesario

- Evitar la sobrecarga de fluidos

- Terapia antibiótica empírica si se sospecha coinfección bacteriana

- Monitorización de la dinámica uterina y el bienestar fetal

- Ventilación mecánica precoz en caso de deterioro de la función respiratoria

- Individualizar el momento más adecuado del parto

- Al alta del servicio la paciente debe recibir una buena orientación / consejería para que regrese al establecimiento de salud tan pronto como presente síntomas de alarma.

- Todos los recién nacidos de madres con COVID-19 positivo deben tener estricto monitoreo para detección temprana de cualquier riesgo o complicación, y debe asegurarse su seguimiento al alta con su referencia al servicio correspondiente.

- Las gestantes o puérperas atendidas por sospecha de COVID-19 deben tener apoyo en salud mental, con énfasis a complicaciones maternas y neonatales ${ }^{1,2,5,8-10}$.

\section{FINALIZACIÓN DEL EMBARAZO}

- La vía y momento del parto deben ser evaluados de forma individual y multidisciplinaria. La decisión de realizar un parto por vía vaginal o de una cesárea debe ser evaluada teniendo en cuenta en primer lugar el criterio obstétrico si el estado de salud de la madre no permitiera un parto vaginal y en segundo lugar el principio de precaución y de protección para el personal que la asiste, que deberá llevar el EPP (Equipo de protección personal) I correspondiente.

- Los servicios de atención de salud materna (salas de parto y operaciones) y neonatal deben estar separadas de las unidades que se atienden los casos de COVID-19 1,5,8-10

\section{LACTANCIA MATERNA}

La OMS recomienda mantener el amamantamiento tanto para casos de madres confirmadas como probables, siempre y cuando se mantengan medidas para la prevención de infección por microorganismos transmitidos por gotas y por contacto. En casos de madres con enfermedad grave recurrir a la extracción de la leche ${ }^{1,9,10}$.

\section{RECOMENDACIONES GENERALES A LAS EMBARAZADAS}

\section{- Durante el embarazo:}

- Lavado frecuente de manos Al toser o estornudar cubrirse la nariz y la boca con el codo flexionado.

- Evitar tocarse los ojos, nariz y boca ya que las manos facilitan la trasmisión.

- Usar pañuelos desechables para eliminar secreciones respiratorias y tíralo tras su uso

- Evitar aglomeraciones y transporte público.

- Limitar las relaciones sociales.

- Limitar los viajes a los estrictamente necesarios.

\section{- Recomendaciones durante el puerperio:}

- Lavado frecuente de manos

- Al toser o estornudar cúbrete la nariz y la boca con el codo flexionado

- Evitar tocarse los ojos, nariz y boca ya que las manos facilitan su trasmisión

- Usar pañuelos desechables para eliminar secreciones respiratorias y tíralo tras su uso

- Evitar aglomeraciones y transporte público

- Limitar las relaciones sociales

- Limitar los viajes

- Limitar las visitas en hospital y casa durante la epidemia

En caso de sintomatología, autoaislarse en el domicilio y ponerse en contacto con los servicios sanitarios según las recomendaciones vigentes en la comunidad autónoma.

\section{PLANIFICACIÓN FAMILIAR}

La Dirección de Salud Sexual y Reproductiva (DSARE) del MINSA recomienda garantizar la continuidad del suministro de métodos anticonceptivos durante esta emergencia nacional en los establecimientos de salud, a través de las siguientes modalidades ${ }^{8}$.

- Establecer un área de salud sexual y reproductiva, según la realidad local, en las áreas de emergencia, a fin de garantizar continuidad de métodos anticonceptivos (en caso que se requiera retiro y colocación de un nuevo implante subdérmico) y la atención de la prevención del embarazo no deseado (AOE).

- Coordinar con farmacia para que todos los métodos anticonceptivos se encuentren en emergencia, especialmente levonorgestrel (AOE). 
- Continuar la atención de planificación familiar y la administración en los establecimientos de salud de primer nivel de anticonceptivos sin necesidad de tener historia clínica (como en campañas) y solo a través de padrones, HIS o receta, para que sea más rápida la atención y evitar filas de espera y aglomeraciones.

- Brindar una dotación de métodos anticonceptivos a nuevas o continuadoras mínimo para tres meses.

- Colocar anuncios visibles en las áreas de consultorio, emergencia o triaje, sobre la atención permanente en Planificación Familiar y la gratuidad de la entrega del método.

- Debe tenerse presente, según la experiencia en otros países, los casos de violencia se han incrementado, por la menor atención prestada a la salud mental en situaciones de aislamiento social. Por tanto, los servicios de emergencia deben garantizar la provisión del kit de violencia sexual.

Financiamiento: Autofinanciado.

Conflicto de interés: Los autores declaran no tener algún conflicto de intereses.

\section{REFERENCIAS BIBLIOGRÁFICAS}

1. Documento técnico Manejo de la mujer embarazada y en el recién nacido con COVID-19. Dirección de Salud Pública e innovación. Ministerio de Sanidad Gobierno de España 17 marzo 2020.

2. Resolución Ministerial 084-2020/MINSA que aprueba el documento técnico: Atención y manejo de casos clínicos de COVID-19. Ministerio de Salud. 7 de marzo 2020.
3. Chen H, Guo J, Wang C, Luo F, Yu X, Zhang W, et al. Clinical characteristics and intrauterine vertical transmission potential of COVID-19 infection in nine pregnant women: a retrospective review of medical records. Lancet 2020; DOI:10.1016/S01406736(20)30360 http://www.sciencedirect.com/science/article/ pii/S0140673620303603.

4. Zhu H, Wang L, Fang C, Peng S, Zhang L, Chang G, et al. Clinical analysis of 10 neonates born to mothers with 2019-nCoV pneumonia. Transl Pediatr 2020;9:51-60: http:// tp.amegroups.com/article/view/35919/28274.

5. Favre G, Pomar L, Musso D, Baud D. 2019-nCoV epidemic: what about pregnancies?. Lancet. 2020; DOI: 10.1016/ S0140-6736(20)30311-1.

6. Qi Lu, Yuan Shi. Coronavirus disease (COVID-19) and neonate: What neonatologist need to know. doi: 10.1002/ jmv. 25740

7. Interim Guidance on Breastfeeding for a Mother Confirmed or Under Investigation For COVID-19. CDC. Consultado 06/03/2020: : https://www.cdc.gov/coronavirus/2019- ncov/ specific-groups/pregnancy-guidance-breastfeeding.html

8. Ministerio de Salud. COVID-19 DSARE 200320-1. Dirección de Salud Sexual y Reproductiva.

9. Guía provisional para establecimientos de salud: preparación para la transmisión comunitaria de COVID-19 en los Estados Unidos. Colegio Estadounidense de Obstetras y Ginecólogos y la Sociedad de Medicina Materno-Fetal. ACOG 18 marzo 2020

10. Wu Z, McGoogan JM. Características y lecciones importantes del brote de la enfermedad por coronavirus 2019 (COVID-19) en China. JAMA [Internet] 2020;disponible en: https://jamanetwork. com/journals/jama/fullarticle/2762130 icono externo

\section{Correspondencia:}

Sociedad Peruana de Obstetricia y Ginecología

Dirección: Av. Aramburú 321 Oficina 4. San Isidro, Lima - Perú

Correo: spogperu@gmail.com

Teléfono: 4214251 